\title{
A gold nanoshell with a silica inner shell synthesized using liposome templates for doxorubicin loading and near-infrared photothermal therapy
}

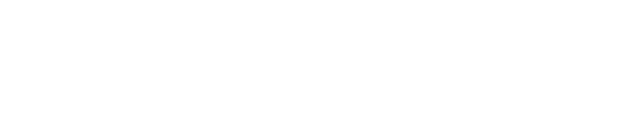

\section{Congyu $\mathrm{Wu}^{\mathrm{I}}$ \\ Cong Yu' \\ Maoquan $\mathrm{Chu}^{1,2}$ \\ 'School of Life Science and Technology, ${ }^{2}$ The Institute for Advanced Materials and Nano Biomedicine, Tongji University, Shanghai, People's Republic of China}

Correspondence: Maoquan Chu School of Life Science and Technology, Tongji University, Shanghai 200092, People's

Republic of China

Tel +862I 65982586

Fax +86 21 65988653

Email mqchu98@tongji.edu.cn

\begin{abstract}
Gold ( $\mathrm{Au}$ ) nanoshells with solid silica cores have great potential for cancer photothermal therapy. However, this nanostructure cannot carry enough drugs. Here, we report a Au nanoshell with a hollow silica core for drug loading and cancer therapy. The silica shells were synthesized using nanoliposome templates, and then Au nanoshells were grown on the outer surface of the silica shells. Transmission-electron and scanning-electron microscopy showed that the Au nanoshells were successfully fabricated, and that the liposome $/ \mathrm{SiO}_{2} / \mathrm{Au}$ coreshell nanocomposites were spherical with a narrow size distribution. Images of several broken spheres, and the fact that hollow templates (liposomes) were used, suggest that the fabricated Au nanoshells were hollow. After doxorubicin (DOX) was incorporated into liposome $/ \mathrm{SiO}_{2} / \mathrm{Au}$, the DOX-loaded Au nanoshells killed cancer cells with high therapeutic efficacy when irradiated with near-infrared light, suggesting that the Au nanoshells delivered both DOX chemotherapy and photothermal therapy with a synergistic effect.
\end{abstract}

Keywords: gold nanoshell, liposome template, synthesis, doxorubicin, cancer therapy

\section{Introduction}

Gold $(\mathrm{Au})$ nanoparticles have been widely used in biomedical research areas for biomolecular, cell, and tissue labeling for many decades. In recent years, Au nanomaterials have attracted greater attention from researchers ${ }^{1}$ because it was demonstrated that Au nanomaterial structures have great potential for cancer photothermal therapy. These special nanostructures, including nanoshells, ${ }^{2-8}$ nanocages, ${ }^{9,10}$ nanocubes, ${ }^{11}$ and nanorods, ${ }^{12,13}$ have a strong surface plasmon resonance in the near-infrared (NIR) region. This benefits in situ cancer therapy because these Au nanostructures can be excited by NIR radiation, which can penetrate tissue more deeply than irradiation with shorter wavelengths. Au nanoshells are composed of a dielectric nanocore covered by an ultrathin Au shell. The resonant wavelength of the Au nanoshell can be easily turned to the NIR band through adjustments of the shell size and thickness. The shell structures are usually stable because the shells are firmly fixed on water-insoluble solid nanocores.

All Au nanoshells have been synthesized using a template-mediated method. These templates include silica nanospheres, ${ }^{2}$ polystyrene (PS) nanospheres, ${ }^{4}$ and poly(lacticco-glycolic acid) (PLGA) nanospheres. ${ }^{5}$ The complexity of core-shell formation is mainly dependent on the core (template) formation method. Au shells are synthesized in a similar manner (Au chloride hydrate is reduced by a reducing agent). The forma- 
tion method of the silica nanocores usually consists of one simple step: the hydrolyzation of tetraethyl orthosilicate (TEOS) in alkaline aqueous solution. This is more convenient and simpler than that of the PLGA or PS nanocores, which are prepared through emulsified-solvent evaporation or emulsion polymerization methods consisting of several steps. However, previously reported Au nanoshells containing silica cores could not be loaded with enough drug for practical use because the inorganic silica nanoparticles are a solid structure. $^{2}$

In this work, hollow silica cores were synthesized and used as templates to prepare drug-loaded Au nanoshells for cancer therapy. Lipid vesicles (liposomes) have been used as templates to prepare hollow materials. ${ }^{14-16}$ Therefore, we used nanoscale liposomes as templates for the synthesis of silica shells through the hydrolyzation of TEOS. The obtained silica shells were then coated with Au shells through the reaction of Au chloride tetrahydrate and hydroxylamine. This novel method for the preparation of Au nanoshells with silica inner shells is quite simple. The liposome templates were formed by the self-assembly of a lipid in water and the growth of the silica and $\mathrm{Au}$ shells was a heterogeneous nucleation process. Because the liposome cores are hollow, doxorubicin (DOX) can be incorporated into the nanocomposites. It has been demonstrated that NIR lasers can be used to excite the metallic nanoparticles, and induce drug release from the nanocomposites, which supplies a dose of both drugs and metallic nanoparticles. ${ }^{17}$ The DOX-loaded Au nanoshells killed cancer cells after being irradiated by NIR light and showed a synergistic effect of chemotherapy and photothermal therapy. The novel drug-loaded Au nanoshell structure prepared and applied in this work will be of interest to both material scientists and biologists.

\section{Materials and methods Materials}

The Au chloride tetrahydrate $\left(\mathrm{HAuCl}_{4}\right)$, hydroxylamine $\left(\mathrm{NH}_{2} \mathrm{OH}, 50\right.$ wt.\% solution in water) were purchased from Sigma-Aldrich (St Louis, MO). The soybean lecithin, cholesterol, TEOS, aminopropyltrithoxy silane (KH-550), trichloromethane, ethanol, $\mathrm{NaOH}$, dimethyl sulfoxide (DMSO), and distilled water were purchased from Sinopharm Chemical Reagent Co., Ltd (Shanghai, China). DOX was obtained from Shanghai Humanity Hospital. The propidine Iodide (PI) and Hoechst33342 were purchased from Sigma-Aldrich. The human liver cancer cells (SMMC-7721) were ordered from the Chinese Academy of Sciences (Shanghai, China). The RPMI-1640 culture medium and fetal calf serum (FCS) were obtained from Gibco (Carlsbad, CA). 3-(4,5)-dimethylthiahiazo(-z-y1)3,5-diphenytetrazoliumromide (MTT) was purchased from Shanghai Haoran Biological Technology Co., Ltd. (Shanghai, China).

\section{Silica-coated liposome nanocomposites synthesis}

The soybean lecithin $(120 \mathrm{mg})$ and cholesterol $(8 \mathrm{mg})$ were dissolved in chloroform $(1 \mathrm{~mL})$ in a round-bottomed flask and dried via rotary evaporation by blow-drying with flowing nitrogen gas to make a thin film. The film was then further blow-dried for about 30 minutes with nitrogen gas to remove the last traces of chloroform. Distilled water $(8 \mathrm{~mL})$ was added to the flask to hydrate the dried lipid film, the contents were gently shaken, and then sonicated for about 30 minutes in nitrogen. The liposome dispersion was extruded through polycarbonate membrane filters (Sinopharm Chemical Regent Co., Ltd), which had pore diameters of $200 \mathrm{~nm}$. The liposome suspension was diluted with distilled water (liposomes: water $=1: 3(\mathrm{v} / \mathrm{v})$ ), and the $\mathrm{pH}$ was adjusted to 10.8 with $\mathrm{NaOH}$. TEOS (100 $\mu \mathrm{L}$; containing 33\% (v/v) ethanol) was then added into the diluted liposome suspension $(4 \mathrm{~mL})$ and gently stirred at room temperature. Twenty-four hours later, the stirring was stopped and the silica-coated liposome (liposome $/ \mathrm{SiO}_{2}$ ) suspension was then stored at $4^{\circ} \mathrm{C}$ in a refrigerator.

\section{Gold nanoshell synthesis}

The distilled-water-diluted KH550 $(20 \mu \mathrm{L}, 6 \mathrm{~mol} / \mathrm{L})$ was mixed with the liposome $/ \mathrm{SiO}_{2}$ suspension $(200 \mu \mathrm{L})$ for about 2 hours. $\mathrm{HAuCl}_{4}$ aqueous solution $(50 \mu \mathrm{L} ; 4 \mathrm{mM}$; $\mathrm{pH} 6.5$, adjusted by $\mathrm{NaOH}$ ) and $\mathrm{NH}_{2} \mathrm{OH}$ aqueous solution $(25 \mu \mathrm{L} ; 2 \mathrm{mmol} / \mathrm{L})$ were added to the mixture under gentle stirring. After a 10-minute incubation, a higher-concentration $\mathrm{HAuCl}_{4}$ solution $(50 \mu \mathrm{L} ; 40 \mathrm{mM}$; $\mathrm{pH} 6.5)$ was added. Then the $\mathrm{NH}_{2} \mathrm{OH}$ solution $(400 \mu \mathrm{L} ; 20 \mathrm{mmol} / \mathrm{L})$ was added to the mixture drop by drop. After the addition of $\mathrm{NH}_{2} \mathrm{OH}$ was finished, the reaction solution was continuously stirred for 10 minutes. The suspension was precipitated via centrifugation. The precipitate was washed with water and then freeze-dried for 72 hours.

\section{Fabrication of DOX-loaded liposome $/ \mathrm{SiO}_{2} / \mathrm{Au}$}

The liposome $/ \mathrm{SiO}_{2} / \mathrm{Au}$ precipitate $(5 \mathrm{mg}$ ) was added to DOX aqueous solution $(200 \mu \mathrm{L} ; 1.78 \mathrm{mg} / \mathrm{mL})$ and incubated at room temperature. Twelve hours later, the suspension was 
precipitated via centrifugation and washed once with water to remove the free DOX. The washed precipitate was then resuspended in a serum-free RPMI 1640 medium before cell experimentation. A schematic of the whole DOX-loaded liposome $/ \mathrm{SiO}_{2} / \mathrm{Au}$ formation process described above is shown in Figure 1.

\section{Characterization of the liposome/SiO $/ 2 \mathrm{Au}$}

The liposome $/ \mathrm{SiO}_{2}$ and liposome/ $/ \mathrm{SiO}_{2} / \mathrm{Au}$ aqueous suspensions were air-dried onto carbon-coated grips, and then examined at $80 \mathrm{kV}$ using a transmission electron microscopy (TEM; JSM-6360LV; JEOL, Tokyo, Japan). The morphology of liposome $/ \mathrm{SiO}_{2} / \mathrm{Au}$ was also observed using a scanning electron microscopy (SEM; JSM-6360LV; JEOL) equipped with energy-dispersive X-ray spectrometry (EDS; JEM-1200EX/S; JEOL). Before SEM observation, the sample was freeze-dried at $-70^{\circ} \mathrm{C}$ for 48 hours. The size distributions were measured via SEM analysis of a 200-particle sample. Ultraviolet-visible (UV-Vis) absorption spectra were taken on a diode array spectrophotometer (UV-2102PC; Unico, Beijing, China) with a deuterium-lamp source. X-ray diffraction (XRD) patterns were recorded on a D8 DISCOVER with a GADDS diffractometer (Bruker AXS, Karlsruhe, Germany) using $\mathrm{Cu} \mathrm{K} \alpha$ $(\lambda=0.15418 \mathrm{~nm})$ radiation.

\section{In vitro release experiments}

A $200-\mu \mathrm{L}$ DOX-loaded liposome/ $\mathrm{SiO}_{2} / \mathrm{Au}$ suspension with concentration of about $15 \mathrm{mg} / \mathrm{mL}$ was loaded into a small plastic centrifugal tube at room temperature, and irradiated using a NIR laser (wavelength: $808 \mathrm{~nm}$; power: $100 \mathrm{~mW}$; spot area: $5 \times 8 \mathrm{~mm}$ ) for 15 minutes in a dark room. The irradiated suspension was then centrifuged immediately. The supernatant solution was measured through UV-Vis

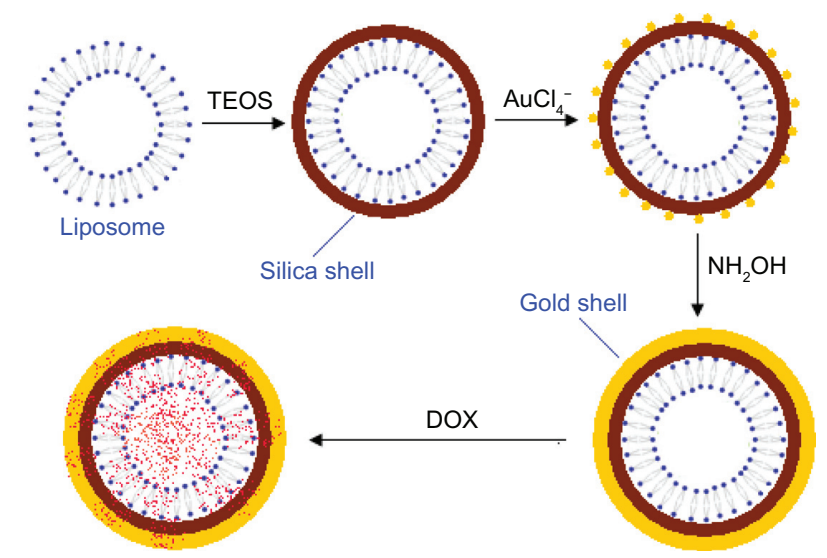

Figure I Schematic of the formation of a DOX-loaded gold nanoshell (DOXloaded liposome/ $\mathrm{SiO}_{2} / \mathrm{Au}$ ).

Abbreviations: DOX, doxorubicin; TEOS, tetraethyl orthosilicate. absorbance taken on a diode array spectrophotometer (UV-2102PC; Unico, Shanghai, China) with a deuterium lamp source. As a control, a DOX-loaded liposome $/ \mathrm{SiO}_{2} / \mathrm{Au}$ suspension containing the same volume and same concentration as the above suspension was placed at room temperature for 15 minutes in the dark room, and the suspension was also centrifuged and the supernatant solution obtained was then measured through UV-Vis absorbance. All experiments were conducted in triplicate.

\section{Cell experiments}

Human liver cancer cells (SMMC-7721) were cultured in a RPMI-1640 medium, which was $10 \%$ FCS and $1 \%$ antibiotic-antimycotic, at $37^{\circ} \mathrm{C}$ in an incubation chamber containing 5\% $\mathrm{CO}_{2}$. The serum-free RPMI 1640 mediumdispersed DOX-loaded liposome $/ \mathrm{SiO}_{2} / \mathrm{Au}$ (containing $250 \mu \mathrm{g} / \mathrm{mL}$ of liposome $/ \mathrm{SiO}_{2} / \mathrm{Au}$ and $22 \mu \mathrm{g} / \mathrm{mL}$ of DOX), liposome $/ \mathrm{SiO}_{2} / \mathrm{Au}(250 \mu \mathrm{g} / \mathrm{mL})$, and DOX $(22 \mu \mathrm{g} / \mathrm{mL})$ were added into six wells of cells and incubated with the cells. Each type of material was incubated with two wells of cells. After a 1-hour incubation, three wells of cells incubated with DOX-loaded liposome/ $\mathrm{SiO}_{2} / \mathrm{Au}$, liposome/ $\mathrm{SiO}_{2} / \mathrm{Au}$, and DOX were irradiated using the $808-\mathrm{nm}$ laser for 15 minutes. As a control, the other three wells of cells were not irradiated by the laser. To evaluate the cell viability, fluorescent dyes (PI $[10 \mu \mathrm{g} / \mathrm{mL}]$ and Hoechst33342 [3 $\mu \mathrm{g} / \mathrm{mL}])$ were then added to the above six wells, which were incubated for 20 minutes. The cells were imaged with an upright fluorescent microscope (Leica DME, Wetzlar, Germany). The in vitro cell viability was evaluated using a MTT assay. The experimental details were as follows: SMMC-7721 cells were seeded onto 96-well plates and incubated in $200 \mu \mathrm{L}$ of the medium at $37^{\circ} \mathrm{C}$ in $5 \% \mathrm{CO}_{2}$ for 24 hours before treatment. There were three treatment groups: cells being incubated with DOX $(22 \mu \mathrm{g} / \mathrm{mL}$ in RPMI 1640, $100 \mu \mathrm{L})$, liposome $/ \mathrm{SiO}_{2} / \mathrm{Au}(250 \mu \mathrm{g} / \mathrm{mL}$ in RPMI $1640,100 \mu \mathrm{L})$, and DOX-liposome $/ \mathrm{SiO}_{2} / \mathrm{Au}(272 \mu \mathrm{g} / \mathrm{mL}$ in RPMI 1640, $100 \mu \mathrm{L}$ ), which were irradiated with NIR light for 15 minutes. Another three identical treatment groups were incubated but without NIR laser irradiation. The cells incubated with RPMI 1640 (100 $\mu \mathrm{L}$ for each well) served as the control group. After a 75-minute incubation, MTT $(5 \mathrm{mg} / \mathrm{mL}$ in phosphate-buffered saline, $20 \mu \mathrm{L}$ ) was added into each well of the plate. Four hours later, the suspensions were replaced with $200 \mu \mathrm{L}$ of DMSO, and the cell viability of each group was determined by measuring their absorbance at $570 \mathrm{~nm}$ using a Flexstation III enzyme-labeled instrument (Molecular Devices, Sunnyvale, CA). 


\section{Results and discussion}

The liposomes $/ \mathrm{SiO}_{2}$ before and after Au coating were generally spherical. However, their detailed morphologies are quite different. In the TEM image of the silica-coated liposome (liposome/ $\mathrm{SiO}_{2}$ ), the contrast between the dark edge and pale center suggests that it is hollow (Figure 2A). Liposomes are hollow lipid vesicles, but their membranes are hard to observe via TEM unless the liposomes are negatively stained using a special reagent (such as phosphotungstic acid). Therefore, the dark shells suggest that $\mathrm{SiO}_{2}$ grew on the outer surface of the liposomes. Hydrolyzation of TEOS on the lipid membrane is a heterogeneous nucleation process. The lipid membranes can lower the activation energy of nucleation. Therefore, the nucleation rate of $\mathrm{SiO}_{2}$ deposition on the liposomes may be improved. This may be the main reason why the lipid membrane can be used as template for silicashell formation. Because a silica shell that is synthesized in alkaline solution is negatively charged, we modified the silica shells with KH550, a silane-coupling agent with an amido group $\left(-\mathrm{NH}_{2}\right)$. The silica shells with positively charged $-\mathrm{NH}_{3}{ }^{+}$ surface groups in aqueous solution can capture negatively charged $\mathrm{AuCl}_{4}^{-}$. The $\mathrm{HAuCl}_{4}$ was, therefore, reduced by the reducing agent $\left(\mathrm{NH}_{2} \mathrm{OH}\right)$ on the silica shells. After $\mathrm{NH}_{2} \mathrm{OH}$ was added into the mixture of liposome $/ \mathrm{SiO}_{2}$ and $\mathrm{HAuCl}_{4}$, the hollow structures of the liposome $/ \mathrm{SiO}_{2}$ were difficult to observe (Figure 2B), which indicated that the hollow silica spheres were successfully coated with Au shells. Au materials are usually black when viewed via TEM. Au nanoparticles have been widely used for cell and tissue labeling because their black appearance can be easily distinguished from the background. The hollow morphology of the nanospheres was

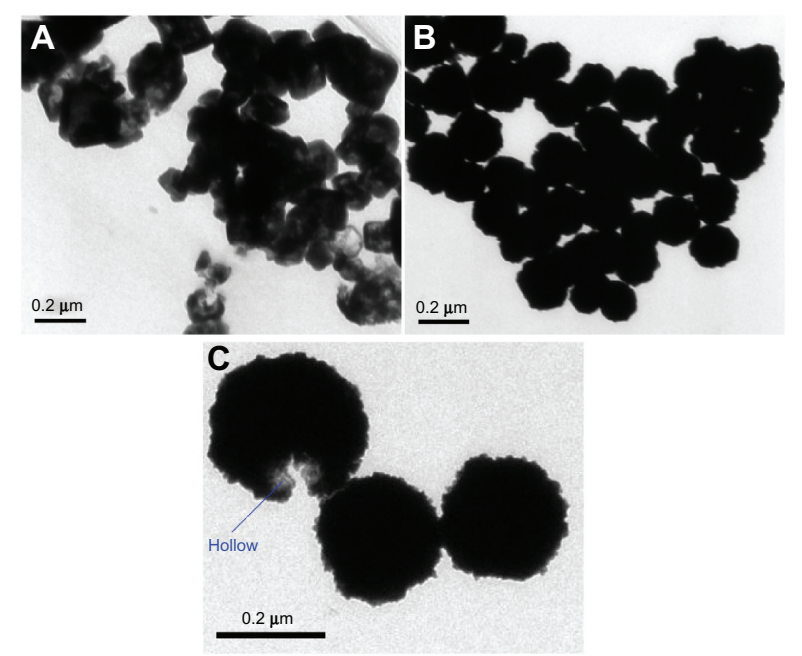

Figure 2 Transmission-electron microscopy images of the A) liposome/ $\mathrm{SiO}_{2}$ and B, C) liposome $/ \mathrm{SiO}_{2} / \mathrm{Au}$ nanospheres. masked by the Au nanoparticles and could not be observed directly. Only from broken liposome/ $\mathrm{SiO}_{2} / \mathrm{Au}$ nanospheres (only a small number of broken nanospheres were found in all the collected TEM images) was the hollow nature observed (Figure 2C).

SEM images of the liposome/ $\mathrm{SiO}_{2} / \mathrm{Au}$ nanospheres indicate that the liposome $/ \mathrm{SiO}_{2}$ nanospheres were successfully coated with $\mathrm{Au}$ shells (Figure 3A). Broken nanospheres served as evidence that the liposome $/ \mathrm{SiO}_{2} / \mathrm{Au}$ nanospheres were hollow (Figure 3A, see the blue frame or the inset at the top right corner of the image). The average diameter, measured from the SEM image, was $238.47 \pm 39.08 \mathrm{~nm}$, which indicates that the liposome $/ \mathrm{SiO}_{2} / \mathrm{Au}$ nanospheres had a narrow size distribution (Figure 3B).

EDS (Figure 4) and XRD (Figure 5) were used to further confirm the formation of the silica and Au shells. After TEOS had been added to the liposome suspension, the EDS spectrum of the product was measured. It showed that the signal intensity corresponding to $\mathrm{O}$ was significantly enhanced and a new strong signal (Si) appeared. These results and the fact that the hydrolysate of TEOS is $\mathrm{SiO}_{2}$ imply that the hollow nanoparticles shown in Figure 2A were silica shells. After $\mathrm{HAuCl}_{4}$ and $\mathrm{NH}_{2} \mathrm{OH}$ were introduced into the liposome $/ \mathrm{SiO}_{2}$ suspension, a strong Au signal appeared in the EDS spectrum of the product. This result combined with the TEM images shown in Figure 2B (or Figure 2C) imply that the liposome/ $\mathrm{SiO}_{2}$ nanoparticles were coated with $\mathrm{Au}$ shells. Compared with the XRD pattern of the liposome $/ \mathrm{SiO}_{2}$ nanospheres, XRD pattern of the liposome/ $\mathrm{SiO}_{2} / \mathrm{Au}$ nanospheres had four additional diffraction peaks at $2 \theta=38.2^{\circ}, 44.4^{\circ}, 65.5^{\circ}$, and $77.9^{\circ}$. These four peaks perfectly match the face-centered cubic structure of $\mathrm{Au}$, which also indicates that $\mathrm{Au}$ nanoshells were deposited on the liposome $/ \mathrm{SiO}_{2}$ nanospheres.

The liposome $/ \mathrm{SiO}_{2}$ had only one sharp UV-absorption peak at a wavelength of $302 \mathrm{~nm}$. After being coated with $\mathrm{Au}$ shells, the obtained liposome $/ \mathrm{SiO}_{2} / \mathrm{Au}$ not only contained the sharp peak at about $302 \mathrm{~nm}$, but also a broad absorption band between 500 and $1100 \mathrm{~nm}$, which had a maximum at $810 \mathrm{~nm}$ (Figure 6). Dispersed small $\mathrm{Au}$ nanoparticles have an absorption peak at $520 \mathrm{~nm} .{ }^{10}$ The broad absorption peak between 500 and $1100 \mathrm{~nm}$ implies that most of the small Au nanoparticles on the liposome/ $\mathrm{SiO}_{2}$ surfaces were syncretized with each other and formed continuous shells. The fact that the liposome $/ \mathrm{SiO}_{2} / \mathrm{Au}$ nanospheres show strong NIR absorption ( $>650 \mathrm{~nm}$ ) is interesting, because NIR light energy can be converted into thermal energy by the $\mathrm{Au}$ nanoshells, which provides great potential for photothermal cancer therapy. 

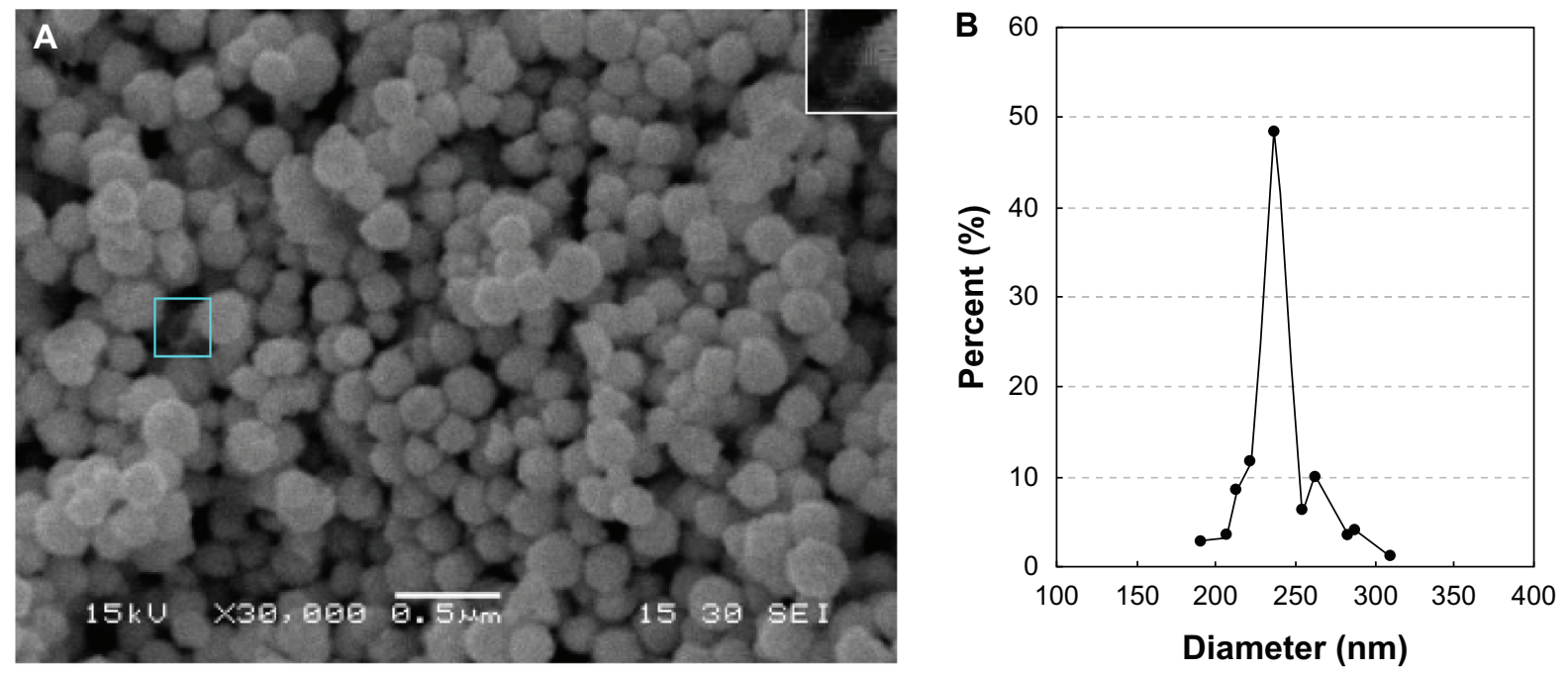

Figure 3 A) Scanning-electron microscopy image and B) size distribution of the liposome $/ \mathrm{SiO}_{2} / \mathrm{Au}$ nanoparticles.

The hollow liposome/ $\mathrm{SiO}_{2} / \mathrm{Au}$ nanoparticles can be used as drug carriers. Here, DOX was selected to be incorporated into these nanocomposites because this water-soluble drug is popularly used for cancer chemotherapy. In this work, $1 \mathrm{mg}$ of liposome $/ \mathrm{SiO}_{2} / \mathrm{Au}$ dry powder was loaded with about $88 \mu \mathrm{g}$ of DOX. DOX has three sharp UV absorption peaks

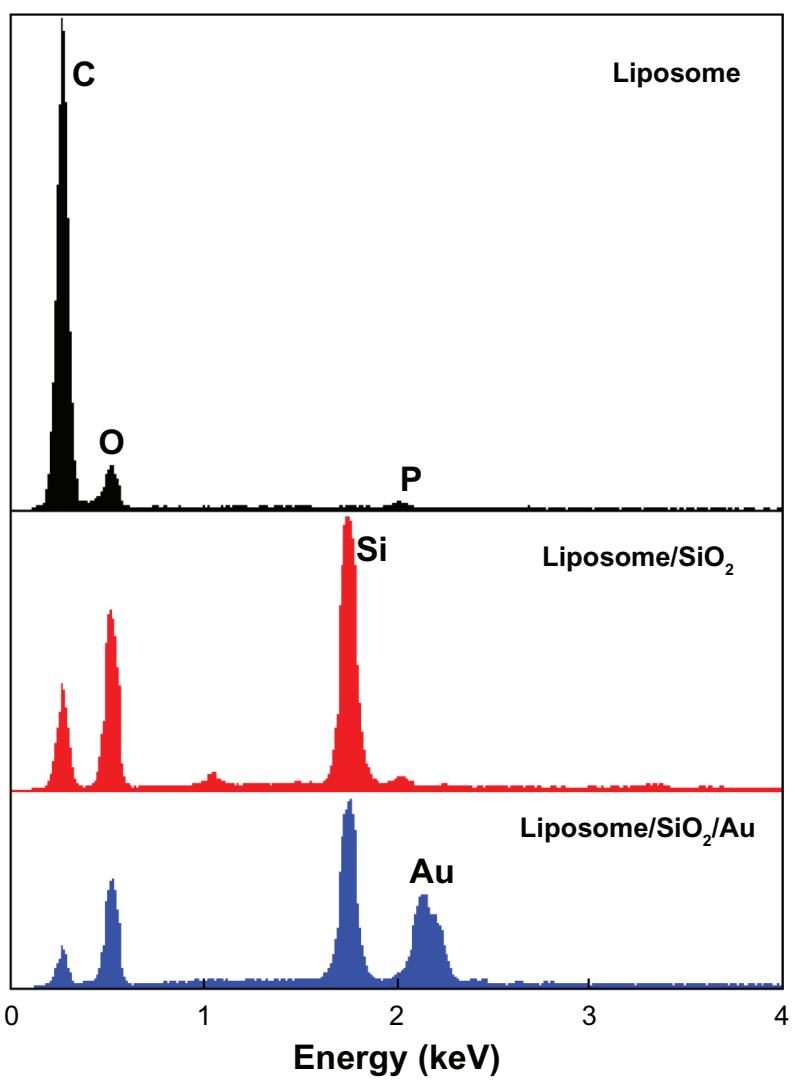

Figure 4 Energy dispersive $X$-ray spectroscopy spectra of the liposome, liposome/ $\mathrm{SiO}_{2}$ and liposome/ $\mathrm{SiO}_{2} / \mathrm{Au}$. at about 233, 254, and $290 \mathrm{~nm}$, respectively. After the DOXloaded liposome $/ \mathrm{SiO}_{2} / \mathrm{Au}$ nanoparticles being irradiated by the $808-\mathrm{nm}$ laser and the suspensions being centrifuged, the absorption peak intensities of the supernatant solutions were obviously higher than those of the supernatant solutions obtained from the DOX-loaded liposome $/ \mathrm{SiO}_{2} / \mathrm{Au}$ nanoparticles without laser irradiation (Figure 7). This indicates that the DOX is rapidly released from the DOX-loaded liposome $/ \mathrm{SiO}_{2} / \mathrm{Au}$ nanoparticles when they are irradiated by NIR light.

From the fluorescence images shown in Figure 8, it can be seen that when the liposome $/ \mathrm{SiO}_{2} / \mathrm{Au}$ and DOX-loaded liposome $/ \mathrm{SiO}_{2} / \mathrm{Au}$ nanoparticles were incubated with human liver cancer cells (SMMC-7721), the viability of only a small amount of cells was reduced. This indicates that the liposome/ $\mathrm{SiO}_{2} / \mathrm{Au}$ before and after being loaded with DOX that had

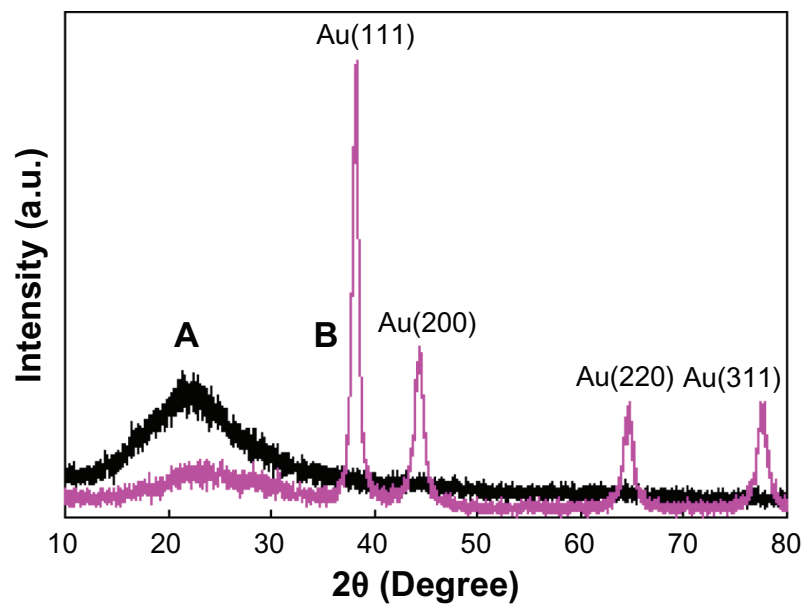

Figure 5 X-ray diffraction patterns of the $\mathbf{A}$ ) liposome $/ \mathrm{SiO}_{2}$ and $\mathbf{B}$ ) liposome/SiO$/$ Au nanoparticles. 


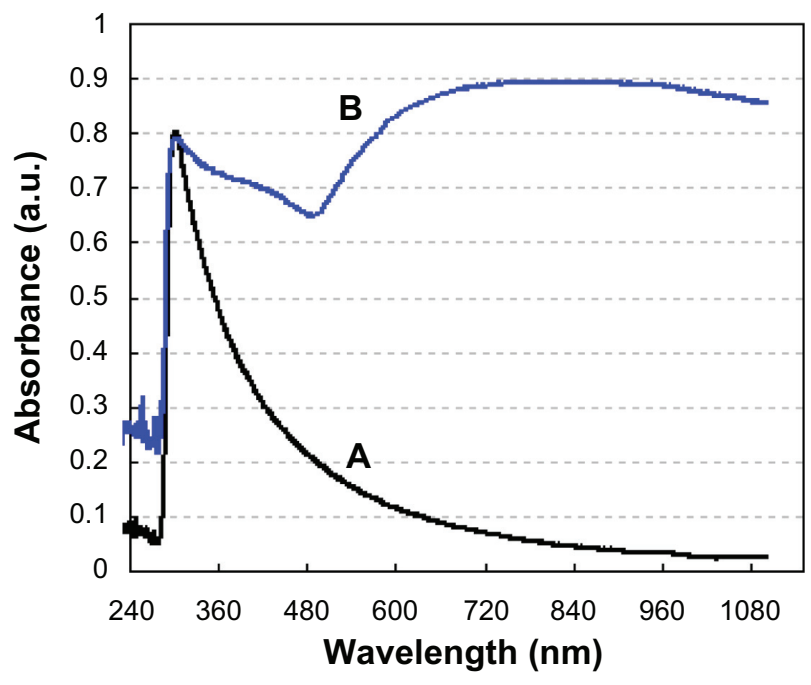

Figure 6 Ultraviolet-visible absorption spectra of the A) liposome/ $\mathrm{SiO}_{2}$ and B) liposome/ $\mathrm{SiO}_{2} /$ Au nanoparticles.

not been irradiated had a low toxicity. After being irradiated by the 808 -nm laser, however, most of the cancer cells were killed by the DOX-loaded liposome/ $\mathrm{SiO}_{2} / \mathrm{Au}$. This suggests that the toxicity of the DOX-loaded liposome $/ \mathrm{SiO}_{2} / \mathrm{Au}$ was stronger than that of the liposome $/ \mathrm{SiO}_{2} / \mathrm{Au}$ without DOX. The viability of the cancer cells incubated with DOX with or without NIR light irradiation was not noticeably different. This may have been because of the lower DOX concentration in the culture medium. In addition, the cell viability described above was more accurately evaluated using a MTT assay. From Figure 9, it can be seen that when the cells were incubated with DOX, liposome $/ \mathrm{SiO}_{2} / \mathrm{Au}$ and DOX-loaded liposome $/ \mathrm{SiO}_{2} /$ Au without laser irradiation, the cell growth inhibition rates were $13.08 \% \pm 3.97 \%, 7.63 \% \pm 3.80 \%$, and $14.27 \% \pm 2.47 \%$,

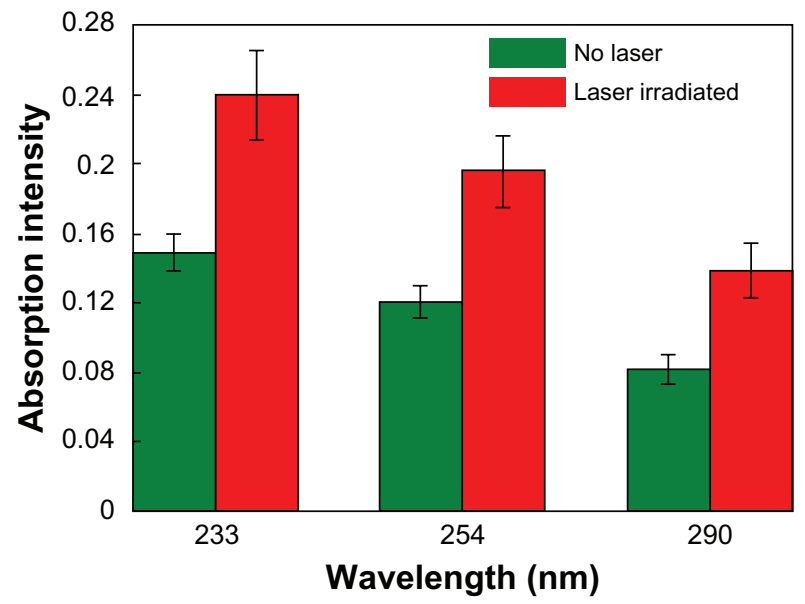

Figure 7 Absorption intensities of the supernatant solutions obtained from the DOX-loaded liposome/SiO $/ \mathrm{Au}$ nanoparticles with and without 808-nm laser irradiation. The higher the absorption intensity, the more the DOX released. Abbreviation: DOX, doxorubicin.
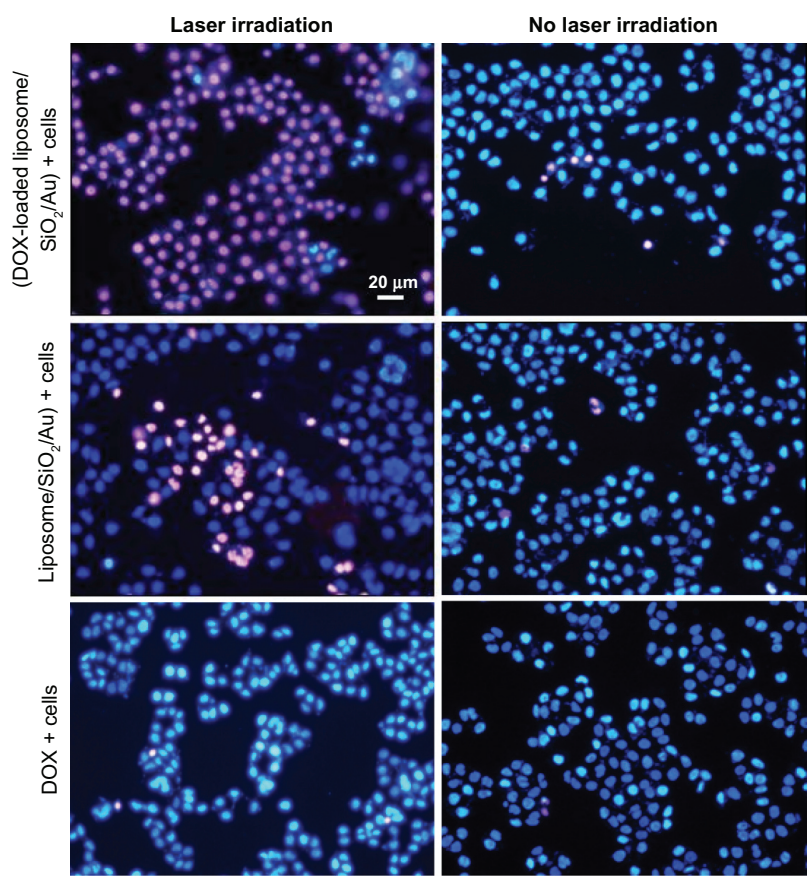

Figure 8 Fluorescence images of the SMMC-772I cells incubated with DOX-loaded liposome $/ \mathrm{SiO}_{2} / \mathrm{Au}$, liposome $/ \mathrm{SiO}_{2} / \mathrm{Au}$, and $\mathrm{DOX}$ for I hour with $808-\mathrm{nm}$ laser irradiation for 15 minutes and without laser irradiation.

Abbreviation: DOX, doxorubicin.

respectively. For the case that cells incubated with DOX and irradiated by laser irradiation, the cell growth inhibition rate was $12.91 \% \pm 5.85 \%$, which was similar to the case without laser irradiation. However, for the case of the laser irradiated cells incubated with liposome/ $/ \mathrm{SiO}_{2} / \mathrm{Au}$ and DOX-loaded liposome $/ \mathrm{SiO}_{2} / \mathrm{Au}$, the cell growth inhibition rates were $57.76 \% \pm 9.36 \%$ and $81.63 \% \pm 4.03 \%$, respectively. These levels were significantly higher than the cases without laser irradiation. Au nanoshells can rapidly convert NIR light energy into local thermal energy and DOX is a common

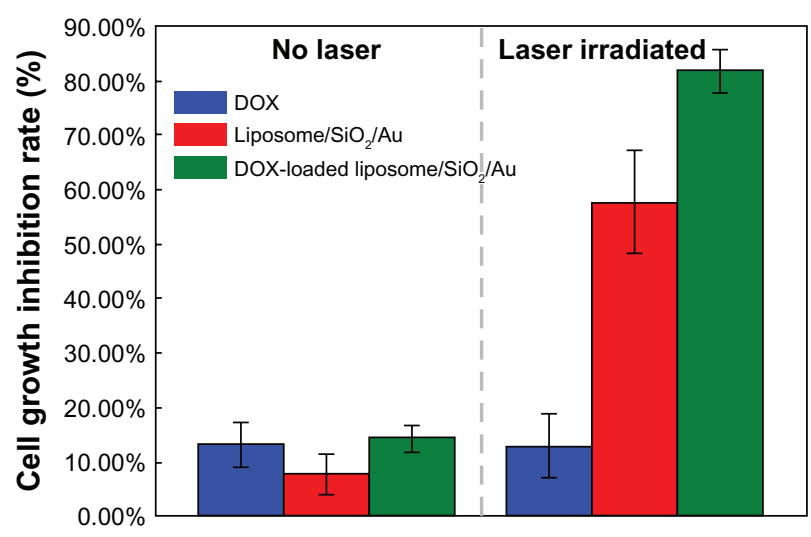

Figure 9 Cell growth inhibition rates after the cells were incubated with DOXloaded liposome $/ \mathrm{SiO}_{2} / \mathrm{Au}$, liposome $/ \mathrm{SiO}_{2} / \mathrm{Au}$, and $\mathrm{DOX}$ with and without $808-\mathrm{nm}$ laser irradiation.

Abbreviation: DOX, doxorubicin. 
chemotherapy drug that remains a popular choice for cancer therapy. The cell toxicity of the samples with DOX-loaded Au nanoshells irradiated by NIR light was significantly stronger than that of the samples with Au nanoshells or DOX alone when irradiated by the same NIR light. This indicates that the DOX-loaded Au nanoshells delivered both chemotherapy and photothermal therapy with a synergistic effect on the cell growth inhibition rate. Similar results have been reported previously. ${ }^{5}$ Because the Au nanoshells synthesized in this work were hollow structures, they may be also used as other chemotherapy drug or photosensitizer carriers in the future. If a photosensitizer was loaded, the nanocomposites may exhibit a similar synergistic effect through the delivery of both photodynamic therapy and photothermal therapy, which should be investigated in future work.

\section{Conclusion}

In summary, hollow $\mathrm{Au}$ nanoshells, composed of lipid vesicle cores (liposomes), silica shell interlayers and a $\mathrm{Au}$ shell outer surface, were successfully synthesized, and DOX was subsequently loaded into these nanocomposites. The nanocomposites obtained were spherical with a narrow size distribution (average diameter: $238.47 \pm 39.08 \mathrm{~nm}$ ). When a NIR laser with a wavelength of $808 \mathrm{~nm}$ was used to irradiate human liver cancer cells (SMMC-7721) incubated with the DOX-loaded Au nanoshells, Au nanoshells, and DOX, the DOX-loaded $\mathrm{Au}$ nanoshells were found to kill the cancer cells more efficiently than the Au nanoshells without DOX or DOX alone. The preparation method of the hollow Au nanoshells described above was simple. In future work, other drugs such as photosensitizers or other chemotherapy agents can be encapsulated into these nanospheres.

\section{Acknowledgments}

We thank Yiming Shou for his assistance with the hollow silica nanosphere preparation. This work was supported in part by the Key Technologies R \& D Program in the 11th Fiveyear Plan of China (2009ZX09103-701) and the National Natural Science Foundation of China (81071833).

\section{Disclosure}

The authors report no conflicts of interest in this work.

\section{References}

1. Cai W, Gao T, Hong H, Sun J. Application of gold nanoparticles in cancer nanotechnology. Nanotechnology, Science and Applications. 2008;1:17-32.

2. Hirsch LR, Stafford RJ, Bankson JA, et al. Nanoshell-mediated nearinfrared thermal therapy of tumors under magnetic resonance guidance. Proc Natl Acad Sci U S A. 2003;100(23):13549-13554.

3. Stern JM, Stanfield J, Kabbani W, Hsieh JD, Cadeddu JA. Selective prostate cancer thermal ablation with laser activated gold nanoshells. J Urol. 2008;179(2):748-753.

4. Liu HY, Chen D, Tang FQ, et al. Photothermal therapy of Lewis lung carcinoma in mice using gold nanoshells on carboxylated polystyrene spheres. Nanotechnology. 2008;19(45):5101-5107.

5. Park H, Yang J, Lee J, Haam S, Choi IH, Yoo KH. Multifunctional nanoparticles for combined doxorubicin and photothermal treatments. ACS Nano. 2009;3(10):2919-2926.

6. Wu G, Mikhailovsky A, Khant HA, Fu C, Chiu W, Zasadzinski JA. Remotely triggered liposomal release by near-infrared light absorption via hollow gold nanoshells. J Am Chem Soc. 2008;130(26):8175-8177.

7. Lowery AR, Gobin AM, Day ES, Halas NJ, West JL. Immunonanoshells for targeted photothermal ablation of tumor cells. Int J Nanomedicine. 2006;1(2):149-154.

8. Gobin AM, Lee MH, Halas NJ, James WD, Drezek RA, West JL. Near-infrared resonant nanoshells for combined optical imaging and photothermal cancer therapy. Nano Lett. 2007;7(7)1929-1934.

9. Chen J, Wang D, Xi J, et al. Immuno gold nanocages with tailored optical properties for targeted photothermal destruction of cancer cells. Nano Lett. 2007;7(5):1318-1322.

10. Skrabalak SE, Au L, Lu X, Li X, Xia Y. Gold nanocages for cancer detection and treatment. Nanomedicine. 2007;2(5):657-668.

11. Wu X, Ming T, Wang X, Wang P, Wang J, Chen J. High-photoluminescenceyield gold nanocubes: for cell imaging and photothermal therapy. ACS Nano. 2010;4(1):113-120.

12. Hauck TS, Jennings TL, Yatsenko T, Kumaradas JC, Chan WCW. Enhancing the toxicity of cancer chemotherapeutics with gold nanorod hyperthermia. Adv Mater. 2008;20(20):3832-3838.

13. Huang X, El-Sayed IH, Qian W, El-Sayed MA. Cancer cell imaging and photothermal therapy in the near-infrared region by using gold nanorods. J Am Chem Soc. 2006;128(6):2115-2120.

14. Bégu S, Aubert Pouëssel A, Lerner DA, Tourné-Péteilh C, Devoisselle JM. Liposil, a promising composite material for drug storage and release. $J$ Control Release. 2007;118(1):1-6.

15. Chu M, Liu G. Synthesis of liposomes-templated CdSe hollow and solid nanospheres. Mater Lett. 2006;60(1):11-14.

16. Tan G, Xu P, He J, Lawson L, McPherson GL, John VT. Highly aspherical silica nanoshells by templating tubular liposomes. Soft Matter 2009;5:3006-3009.

17. Skirtach AG, Javier AM, Kreft O, et al. Laser-induced release of encapsulated materials inside living cells. Angew Chem Int Ed. 2006;45: $4612-4617$.
International Journal of Nanomedicine

\section{Publish your work in this journal}

The International Journal of Nanomedicine is an international, peerreviewed journal focusing on the application of nanotechnology in diagnostics, therapeutics, and drug delivery systems throughou the biomedical field. This journal is indexed on PubMed Central, MedLine, CAS, SciSearch ${ }^{\circledR}$, Current Contents ${ }^{\circledR} /$ Clinical Medicine,

\section{Dovepress}

Journal Citation Reports/Science Edition, EMBase, Scopus and the Elsevier Bibliographic databases. The manuscript management system is completely online and includes a very quick and fair peer-review system, which is all easy to use. Visit http://www.dovepress.com/ testimonials.php to read real quotes from published authors. 